\title{
Rubrics as a Vehicle to Define the Twelve CEAB Graduate Attributes, Determine Graduate Competencies, and Develop a Common Language for ENGINEERING STAKEHOLDERS
}

\author{
Jillian Seniuk Cicek, Sandra Ingram, Nariman Sepehri, J.P. Burak, Paul Labossiere, Danny Mann, Douglas \\ Ruth, Anne Parker, Ken Ferens, Norma Godavari, Jan Oleszkiewicz and Aidan Topping \\ Faculty of Engineering, University of Manitoba, Winnipeg, MB, Canada R3T 5V6 \\ umseniuk@cc.umanitoba.ca
}

\begin{abstract}
This paper discusses the evolution of a set of rubrics for the 12 CEAB graduate attributes in the Faculty of Engineering at the University of Manitoba. The rubrics are intended as a pedagogical assessment tool for instructors of individual courses as applicable, and for assessment at the program level. Individuals from faculty, industry and the University of Manitoba Centre for the Advancement of Teaching and Learning have been involved in the process of evaluating and revising both the content and wording of the rubrics in order that they meet the following criteria: (i) the foci and indicators adequately communicate the knowledge, skills, attitudes, values and behaviours that our engineering stakeholders agree do define each attribute; (ii) the competency level for each indicator is representative of what engineering educators and stakeholders agree defines proficiency; and (iii) the language in the rubrics is consistent and agreeable to all engineering stakeholders. These rubrics are expected to accomplish a number of outcomes-based pedagogical and accreditation goals, including: dividing the attributes into teachable and measurable foci and indicators; defining competency levels; and becoming a vehicle for the development of a common language for faculty, students and industry when they discuss, teach, assess and acquire the knowledge, skills and behaviours of the CEAB graduate attributes. This paper reports on the evolution of these rubrics, and outlines plans for their continued development and use within the faculty.
\end{abstract}

Keywords: rubrics; outcomes-based assessment; CEAB graduate attributes; common language; competencies

\section{INTRODUCTION}

The present Canadian Engineering Accreditation Board (CEAB) requirements are characterized by outcomes-based education, which is "an educational process that fosters continuous attention to student learning and promotes institutional accountability based on student learning" [2]. Rather than focusing solely on what an engineering program has to offer (inputs) [12], accredited Canadian faculties are being asked to look at what students are learning in their programs, or "'those aspects of the student's development that the institution either does influence or attempts to influence through its educational programs and practices" [12]. Specifically, when students graduate, what attributes, or knowledge, skills, attitudes, values and behaviors [12][15] do their programs instill in them that will prepare them for the complexities inherent in their upcoming professional lives [10]. Faculties are required to show "what graduates will be expected to know and be able to do upon completing the program" [17]. In other words, faculties are being asked to focus on student learning outcomes, which are "a stated expectation of what someone will have learned" [2]. This requires engineering faculties seeking accreditation to devise a comprehensive assessment plan, as "the focus of an institution's assessment efforts should be on the measurement of student learning outcomes in a systematic and valid manner" [9]. Components of this plan include assessing individual students and courses, as well as whole engineering programs. Additionally, assessment data are required from a number of sources and from all engineering stakeholders, including students, faculty, alumni, and industry. Changes need to be implemented based on these findings, and then the process begins again, in a continual assessment cycle or feedback loop [17][18].

In order to successfully plan and implement a facultywide assessment protocol, "faculty and administration must have a common language and set of expectations" [9]. Establishing a common language is a foundation for developing a shared understanding and common goals. Also essential is the design of appropriate assessment tools to support outcomes-based education and "[assess] in ways that support student learning" [2]. Outcome assessment is defined as "a method for determining whether students have learned, have retained, and can apply what they have been taught" [16]. Outcome indicators are "the measuring instruments used in assessment, and the means by which achievement of outcomes is confirmed" [15]. CEAB has provided accredited faculties with a list of 12 graduate outcomes that faculties must demonstrate their graduates acquire while in their programs. However, it has been left to individual faculties to organize those attributes into 
learning foci and outcome indicators. These learning indicators must have concrete, measurable values attached to each, thus explicitly stating expectations for both instructors and students. As well, they must be designed to determine the appropriate achievement level or competency of each indicator, so that instructors can target and students can achieve the acceptable level of proficiency. After all, "competencies, as opposed to educational credentials alone, are the foundation of successful professional practice throughout a career, an assumption shared with agencies that grant licenses for individuals to practice professions" [5]. Assessment tools are needed to accomplish this task.

Rubrics are an assessment tool that meets these criteria. Rubrics can be used to define foci and indicators, divide indicators into performance levels, and target the level that indicates competency. They are a tool conducive to outcomes-based education and assessment, and can be used to facilitate a common understanding and language. Above all, "the genius of rubrics is that they are descriptive and not evaluative. Of course, rubrics can be used to evaluate, but the operating principle is you match the performance to the description rather than judge it" (Susan Bookhart, How to Create and Use Rubrics for Formative Assessment) [6].

The Faculty of Engineering at the University of Manitoba is developing a set of rubrics for the $12 \mathrm{CEAB}$ graduate attributes. The rubrics are intended as a pedagogical assessment tool for instructors of individual courses as applicable, and for assessment at the program level. The rubrics are inspired and informed by the VALUE rubrics of the Association of American Colleges and Universities [11]. Individuals from faculty, industry and the University of Manitoba Centre for the Advancement of Teaching and Learning have been involved in the process of evaluating and revising both the content and wording of these rubrics. The objectives of the work are to develop rubrics in which: (i) the foci and indicators adequately communicate the knowledge, skills, attitudes, values and behaviors that our engineering stakeholders agree define each attribute; (ii) the competency level for each indicator is representative of what engineering educators and stakeholders agree defines proficiency; and (iii) the language used in the rubrics is consistent and agreeable to all engineering stakeholders. With the development of these rubrics, we purport to accomplish a number of outcomes-based pedagogical and accreditation goals for the engineering faculty: divide the attributes into teachable and measurable foci and indicators; define competency levels; and develop a common language for faculty, students and industry so that there is a common understanding when they discuss, teach, learn and assess the knowledge, skills, behaviors, values and attitudes inherent in the graduate attributes. The development of, and vision for these rubrics are presented in this paper.

\section{EVOLUTION}

There exist a number of resources that have supported the development of the rubrics for the $12 \mathrm{CEAB}$ graduate attributes at the Faculty of Engineering at the University of Manitoba. This section outlines how these resources were utilized.

\subsection{Association of American Colleges and Universities (AAC\&U): VALUE rubrics [11]}

When the Faculty determined that creating a set of assessment rubrics would be useful in assessing the 12 CEAB graduate attributes, the first step was to see what was "out there," as many programs have or are in the midst of undertaking similar initiatives. It was important to seek out others' experiences rather than "reinvent the wheel" [17] Yet, at the same time, it was vital to look at what the faculty already had in place in terms of assessment, and work to adapt what was there into a new protocol [16].

What was found were the VALUE Rubrics (Valid Assessment of Learning in Undergraduate Education) [11], which are a set of sixteen rubrics that were constructed by "teams of faculty and other academic and student affairs professionals" for the VALUE initiative of the Association of American Colleges and Universities (AAC\&U) [8]. This initiative is described as being "focused on the need to develop direct assessment of student learning to define, document, assess, and strengthen student achievement of the Essential Learning Outcomes (ELOs) in undergraduate education for student success" [3] and were "for use in any institutional context" once we responded to a brief questionnaire [8]. These 16 rubrics became the foundation for our own initiative to develop a set of rubrics for the CEAB graduate attributes.

\subsection{Sub-Committee Evaluation}

Once familiar with the VALUE rubrics, a small subcommittee, comprised of the Associate Dean for Undergraduate programs in charge of overseeing the accreditation process for the faculty, a faculty member in charge of compiling the faculty accreditation data, and a doctoral student with a focus on engineering education, worked together to align the VALUE Rubrics [11] with the 12 CEAB graduate attributes and identify any perceived missing elements (see Table 1).

As soon as a foundation was established for the rubrics, each attribute was partitioned into one or more learning foci, a number of indicators and four performance levels. Additional rubric sources were found $[1][13][14][19][20][21][22]$ for the attributes that were identified as having missing elements (i.e., Knowledge 
Base for Engineering; Investigation; Use of Engineering Tools; Professionalism; and Economics and Project Management). The rubrics were then presented to other groups for feedback (see Appendix B for an example).

Table 1: CEAB Graduate Attributes Aligned with VALUE Rubrics

\begin{tabular}{ll}
\hline CEAB Attribute & VALUE Rubric [11] \\
\hline $\begin{array}{l}\text { 1. Knowledge Base for Engineering } \\
\text { (Need: Science and engineering }\end{array}$ & Quantitative Literacy, Reading \\
knowledge & \\
2. Problem Analysis & Problem Solving, Critical Thinking \\
3. Investigation & $\begin{array}{l}\text { Inquiry and Analysis, Information } \\
\text { Literacy }\end{array}$ \\
4. Design & Inquiry and Analysis, Creative Thinking \\
5. Use of Engineering Tools (Need: & NA \\
Rubric) & Teamwork \\
6. Individual and Team Work & Written Communication, Oral \\
7. Communication Skills & Communication \\
& Civic Engagement \\
8. Professionalism (Need: reflect & \\
professional roles and & \\
responsibilities) & Intercultural Knowledge and \\
9. Impact of Engineering on Society & Competence, Global Learning, Civic \\
and the Environment & Engagement \\
10. Ethics and Equity & Ethical Reasoning \\
11. Economics and Project & NA \\
Management (Need: Rubric) & \\
12. Life-long Learning & Foundations and Skills for Lifelong \\
& Learning, Interactive Learning \\
\hline
\end{tabular}

\subsection{Centre for the Advancement of Teaching and Learning}

The Director for the University of Manitoba Centre for the Advancement of Teaching and Learning was asked to review the rubrics and provide initial feedback. His critique mainly focused on the inconsistency of wording. These irregularities were evident from indicator to indicator, as well as across performance levels. For example, what might indicate a competent performance for one indicator ("Adequately Meets Expectations") might indicate incompetence ("Fails to Meet Expectations") in another. Secondly, the need for concrete, measurable language for all indicators across all performance levels was identified. Areas in the rubrics that already exemplified this were highlighted. This feedback was used as a framework for stakeholders as a focus for their review [7].

\subsection{Industry Forum}

Feedback was sought from Industry members during an Industry forum held in December 2013. Industry participants were given four rubrics for the respective attributes: Problem Analysis, Use of Engineering Tools, Ethics and Equity, and Economics and Project Management. Participants were invited to comment on indicators, language and competency levels. Specifically, industry members were asked if the language used in the rubrics was reflective of the language used in industry; which performance levels would indicate competency for industry; and to consider individual indicators for each attribute. For example, were there superfluous indicators? Repetitive indicators? Missing indicators? The theme of the forum was "toward a common language" [4]. Data from the forum, and concomitantly, from our Academic experts, were used to revise the four rubrics.

\subsection{Academic Experts}

Faculty members whose teaching areas aligned with the graduate attributes were consulted on individual rubrics. Meetings were arranged with each academic expert and the sub-committee, rubrics were discussed, and revisions were made immediately and collaboratively. Feedback was given on the indicators and language, as well as on the format of the rubrics. It was determined that the numerical scales, order of the performance levels, and the wording of the level descriptors had negative connotations. Changes to the rubric format were made to create a more positive assessment tool:

$>$ Performance Levels were changed from Levels 0 3 to Levels $1-4$.

$>$ Level Descriptors were changed from "Fails to Meet Expectations, Minimally Meets Expectations, Adequately Meets Expectations and Exceeds Expectations" to "Needs Work, Developing, Competent, and Strong."

$>$ Example Scores, with letter grades and numerical marks corresponding to each performance level (i.e., Competent $=\mathrm{B}=70-80 \%$ ) were removed.

$>$ The order of the performance levels was reversed. Originally, the rubrics were designed to begin with the lowest performance level, and moved left to right across to the strongest performance level. The order was reversed to begin with strongest performance.

Additionally, indicators and performance levels were streamlined, and the definition of each attribute was rechecked to ensure that the indicators covered all facets of each definition.

As a result of the feedback from stakeholders and the revision process, a number of other sources were used for several attributes, including Knowledge Base for Engineering; Investigation; Communication Skills; Professionalism; Ethics and Equity; Economics and Project Management; and Lifelong Learning. Sources included the ABET Scoring Rubrics for Program Outcomes from the University of Delaware College of Engineering Civil and Environmental Engineering [20], Rubrics for Conducting an Experiment in the Lab from Writing@CSU [22], Basic Listening Rubric from Waypoint Outcomes [21], Student Leader Learning Outcomes from Texas A \& M University [19], Alberta Education Rubric for Asking Questions from Alberta 
Education [1], Rubric for the Role Play of Accepting Criticism [14], and Rubrics for Outcomes Assessment [13].

\subsection{Curriculum Management Committee}

The rubrics have been given to the faculty's Curriculum Management Committee (CMC) members, who are taking them back to their individual engineering departments (see Appendix A for an example). Feedback has been requested and should be guided by the following questions:

- Do foci/indicators sufficiently represent an attribute? Are any indicators missing? Are any unnecessary? Is there any overlap?

- Do indicators match the objectives of your courses?

- Do indicators read consistently across the performance levels?

- Are performance levels measurable?

- Do you agree with the level that indicates competency?

- How does your department envision using these rubrics?

\section{FINDINGS}

The rubrics for the $12 \mathrm{CEAB}$ graduate attributes are still in development. However, through this ongoing process, there have been a number of findings. A culture of engagement is evident, with faculty meeting to discuss the rubrics, and pondering about assessment, teaching and learning. There has been a focus on supporting student learning in the most positive manner possible. The development and revisions of the rubrics have all been informed with student learning at the center of each decision. A common language and understanding is evolving to identify the knowledge, skills, attitudes, values and behaviors inherent in the twelve CEAB graduate attributes, and in the pursuit of establishing common criteria. This is supported in the literature: “....any course and all of its sections need to be directed to some common outcomes in terms of knowledge and understandings, skills, and even attitudes and values. And there need to be common criteria for how well the students must meet those outcomes..." [2]. An unexpected finding has been the enthusiasm that is evident from all stakeholders, including the approximately 30 industry and 17 faculty members who met to discuss four of the rubrics and suggested that we continue the forums [4], the faculty who have been working to develop the rubrics, and the students who have been told about the rubrics as we begin to initiate student feedback.

Generally, at this stage in the development process, $55 \%$ of the rubrics have been specifically designed for the faculty as a result of the exchanges between our stakeholders and the revision process. Of the remaining $45 \%$, which have been mainly informed by the AAC\&U VALUE rubrics [11], the ABET Scoring Rubrics for Program Outcomes from the University of Delaware College of Engineering Civil and Environmental Engineering [20], and Rubrics for Conducting an Experiment in the Lab [22], much of the wording has been revised to suit our stakeholders' needs.

We realize the importance of this process being faculty-initiated in order to foster ownership, and we have witnessed this firsthand. This too is backed by the research: "It is important to recognize that assessment and the consequent improvement in teaching and learning must remain in the hands of faculty instructors...The same is true of the data gathering, analysis and interpretation, and recommendations that achieve much more effective improvement when initiated by the user..." [2]. We also understand that there is much left to do in terms of discussion, revision and implementation [2], but we look forward to the continuation of the process, especially the feedback from our four engineering departments and the inclusion of our engineering students' perspectives.

\section{CONCLUSIONS/FUTURE DIRECTIONS}

Creating a comprehensive outcomes-based assessment protocol is a daunting, yet mandatory task for engineering programs being reviewed by accreditation boards. The task involves faculties establishing a common language and understanding of the graduate attributes. Assessment methods and tools must be identified and/or developed, refined and executed. Feedback must be gathered from all engineering stakeholders, including faculty, students and industry, analyzed, and used to improve existing courses and procedures. In the Faculty of Engineering at the University of Manitoba, work is underway to develop a set of rubrics for each of the $12 \mathrm{CEAB}$ graduate attributes that establish a common language for assessment, define performance levels, target competency levels, and provide faculty, students and industry with a comprehensive assessment tool as part of a comprehensive assessment protocol.

As with all of the initiatives that have been undertaken by the faculty in the move towards establishing an outcomes-based curriculum, unexpected benefits have been gained. The process of developing a common set of assessment tools has facilitated a dialogue about teaching, learning and assessing. It has fostered a community of instructors and industry members excited to establish a common assessment language and create a culture of 
outcomes-based education that focuses on student learning. That being said, the development of the rubrics is still underway. We are in the process of getting student and additional academic feedback, which may lead to further revisions. Two more industry forums will also be hosted specifically to gather feedback on the rubrics, with an upcoming forum planned for April. And there is still the need to discuss the implementation and use of the rubrics. Many questions arise from the processes we have embarked on, including: Do these rubrics represent the profile of an engineer graduating from our programs? Are the indicators that comprise each attribute a suggestion or a standard? Do these rubrics apply to all of the engineering programs within the faculty, or should they be adapted individually for each? And, are competency levels dependent on the course or program, or on the attributes/indicators targeted?

There are other aspirations for the rubrics. They are a tool for teaching, supporting the writing of course objectives and helping target specific attributes and indicators when designing course content and its facilitation. They are a tool for assessment: instructors assessing students and courses (by mapping attributes to courses); department heads assessing programs (using attribute course maps for an overview of programs); students assessing self and peers; and faculty and industry assessing graduates. They are also a foundation for the creation of other assessment tools, such as the development of surveys, including student exit surveys; alumni surveys; industry surveys; and faculty course/program surveys. The data gathered as a result of these processes will be used to inform the faculty's cycle of continuous program improvement. Realizing a comprehensive outcomes-based assessment protocol is no easy task. It is a complicated problem that demands a sophisticated and intelligent design - the perfect job for an engineer.

\section{Acknowledgements}

This research study was made possible by the funding of the NSERC Chair in Design Engineering program at the University of Manitoba; Dr. Ingram's University of Manitoba Faculty of Engineering Start-up Grant; and Jillian Seniuk Cicek's University of Manitoba Graduate Fellowship (UMGF) and Manitoba Graduate Scholarship (MGS). The authors of this paper would also like to thank Mark Torchia, the Curriculum Management Committee, and the Dean's Office of the Faculty of Engineering at the University of Manitoba for their support and feedback.

\section{References}

[1] Alberta Education Online Guide to Implementation, Alberta Education Rubric for Asking Questions. Available as of April 11, 2014 from http://www.learnalberta.ca/content/ssmt/html/docs/askingpo werfulquestions.pdf

[2] Amy Driscoll and Swarup Wood, Developing Outcomesbased Assessment for Learning-centered Education: A Faculty Introduction. Sterling, VA: Stylus, 2007, 275 pp. \{ISBN: 978 I 579221959 \}

[3] Association of American Colleges and Universities, VALUE: Valid Assessment of Learning in Undergraduate Education. Available as of April 11, 2014 from http://www.aacu.org/value/project_description.cfm

[4] Ken Ferens, Jillian Seniuk Cicek, Nariman Sepehri, Witold Kinsner, J.P. Burak, Anne Parker, Dean McNeill, Douglas Ruth, Ian Jeffrey, Norma Godavari, and Sandra Ingram, "Industry Forum III: Towards a common language," in Proc. CEEA Canadian Engineering Education Conf., CEEC14, Sean Maw and Marjan Eggermont (eds.) (Canmore, AB; 811 June 2014), 8 pp., 2014.

[5] Matthew A. Holsapple, Donald D. Carpenter, Janel A. Sutkus, Cynthia J. Finelli, and Trevor S. Harding, "Framing faculty and student discrepancies in engineering ethics delivery," Journal of Engineering Education, vol. 101, no. 2, pp. 169-186, 2012.

[6] Idaho State Department of Education, The Power of Assessment Webinar Series Module 5 Asking Effective Questions. Available as of April 12, 2014 from http://www.sde.idaho.gov/site/formativeInterim/modules/Mo dule $5 /$ Module $\% 205 \% 20$ NOTES\%20(Asking\%20Good\%20 Questions).pdf

[7] Just Do the Right Thing - In the Classroom, Giving Students a Purpose for Their Reading. Available as of April 12, 2014 from http://www.justdotherightthing.org/give-studentspurpose-their-reading

[8] Leap Campus Toolkit: Resources and Models for Innovation, VALUE Rubrics for Assessing Learning. Available as of April 11, 2014 from http://leap.aacu.org/toolkit/learningoutcomes-assessment/2010/value-rubrics-for-assessinglearning

[9] Jack McGourty, Catherine Sebastian, and William Swart, "Developing a comprehensive assessment program for engineering education," Journal of Engineering Education, vol. 87, no. 4, pp. 355-361, 1998.

[10] Honor J. Passow, "Which ABET competencies do engineering graduates find most important in their work?," Journal of Engineering Education, vol. 101, no. 1, pp. 95$118,2012$.

[11] Terrel Rhodes, ed., Assessing Outcomes and Improving Achievement: Tips and Tools for Using Rubrics. Washington, DC: Association of American Colleges and Universities (AAC\&U), 2010. Available as of April 11, 2014 from http://www.aacu.org/value/rubrics/index_p.cfm?CFID $=4103$ $0298 \&$ CFTOKEN $=68905942$. 
[12] Gloria M. Rogers, "EC2000 and measurement: How much precision is enough?," Journal of Engineering Education, vol. 89, no. 2, pp. 161-166, 2000.

[13] Rubrics for Outcome Assessment. Retrieved on October 9, 2013 from:

http://webcache.googleusercontent.com/search?q=cache:4G wd7haic2wJ:www.bae.uky.edu/academics/abet/Rubrics\%252 0 Draft $\% 2520$ July $\% 25202012$. docx $+\& \mathrm{~cd}=1 \& \mathrm{hl}=$ en $\& \mathrm{ct}=\mathrm{clnk}$ $\& \mathrm{gl}=\mathrm{ca} \& \mathrm{client}=$ safari

[14] Rubric For The Role Play On Accepting Criticism. Available as of April 11, 2014 from http://www.cccoe.net/social/constructcritrubric.htm

[15] Katherine Scales, Christi Owen, Subodh Shiohare, and Michael Leonard, "Preparing for program accreditation review under ABET engineering criteria 2000: Choosing outcome indicators," Journal of Engineering Education, vol. 87, no. 3, pp. 207-210, 1998.

[16] Joseph Shaeiwitz, "Outcomes assessment in engineering education," Journal of Engineering Education, vol. 85, no. 3, pp. 239-246, 1996.

[17] Neelam Soundarajan, "Preparing for accreditation under EC 2000: An experience report," Journal of Engineering Education, vol. 91, no. 1, pp. 117-123, 2002.
[18] Joni E. Spurlin, Sarah A. Rajala, and Jerome P. Lavelle, Designing Better Engineering Education Through Assessment. Sterling, VA: Stylus, 2008, 360 pp.

[19] Texas A \& M University, Student Leader Learning Outcomes: Division of Student Affairs. Available as of October 15, 2013 from: http://sllo.tamu.edu/rubrics

[20] University of Delaware College of Engineering Civil \& Environmental Engineering, ABET Scoring Rubrics for Program Outcomes. Available as of October 9, 2013 from http://www.ce.udel.edu/ABET/Current\%20Documentation/A BET_scoring_rubrics_index.html

[21] Waypoint Outcomes, Basic Listening Rubric. Available as of April 11, 2014 from RubricLibrary.com http://rubriclibrary.com/assessment-methodologies/courseembedded-assessment/basic-listening-rubric/

[22] Writing at CSU: The Writing Studio, Rubric for conducting an experiment in the lab. (From D. D. Steven and A. J. Levi, Introduction to Rubrics: An assessment tool to save grading time, convey effective feedback and promote student learning. Sterling, VA: Stylus Publishing, 2005, pp. 96-97.) Available as of October 8, 2013 from http://writing.colostate.edu/guides/teaching/commenting/exp eriment.cfm

\section{APPENDIX A: AN EXAMPLE OF AN EVOLVED RUBRIC}

\begin{tabular}{|c|c|c|c|c|c|}
\hline \multicolumn{6}{|c|}{$\begin{array}{l}\text { 8. Professionalism: An understanding of the roles and responsibilities of the professional engineer in society, especially the primary role of protection } \\
\text { of the public and the public interest. }\end{array}$} \\
\hline \multirow{2}{*}{ Focus Area } & \multirow{2}{*}{ INDICATOR } & Level 1 & Level 2 & Level 3 & Level 4 \\
\hline & & Needs Work & Developing & Competent & Strong \\
\hline & $\begin{array}{l}\text { APEGM Code of Ethics: } \\
\text { Awareness and } \\
\text { understanding of the APEGM } \\
\text { Code of Ethics and the } \\
\text { Professional Engineering Act } \\
\text { of Manitoba. Ability to } \\
\text { evaluate and judge a } \\
\text { situation using facts and the } \\
\text { APEGM Code of Ethics and } \\
\text { the Professional Engineering } \\
\text { Act of Manitoba. }\end{array}$ & $\begin{array}{l}\text { Little awareness/unaware of the } \\
\text { APEGM Code of Ethics and the } \\
\text { Professional Engineering Act of } \\
\text { Manitoba. }\end{array}$ & $\begin{array}{l}\text { Aware of the APEGM Code of } \\
\text { Ethics. Demonstrates some } \\
\text { understanding of APEGM and } \\
\text { the Professional Engineering } \\
\text { Act of Manitoba. }\end{array}$ & $\begin{array}{l}\text { Demonstrates an ability to } \\
\text { evaluate and judge situations } \\
\text { using the APEGM Code of Ethics } \\
\text { and the Professional Engineering } \\
\text { Act of Manitoba. }\end{array}$ & $\begin{array}{l}\text { Demonstrates exemplary ability to } \\
\text { evaluate and judge situations } \\
\text { using the APEGM Code of Ethics } \\
\text { and the Professional Engineering } \\
\text { Act of Manitoba. }\end{array}$ \\
\hline & $\begin{array}{l}\text { Personal and Workplace } \\
\text { Health and Safety: } \\
\text { Awareness and } \\
\text { understanding of personal } \\
\text { and workplace health and } \\
\text { safety. }\end{array}$ & $\begin{array}{l}\text { Unfamiliar with the importance of } \\
\text { personal and workplace health } \\
\text { and safety. } \\
\text { Ignores workplace safety } \\
\text { principles. }\end{array}$ & $\begin{array}{l}\text { Familiar with the importance } \\
\text { of personal and workplace } \\
\text { health and safety, but does } \\
\text { not demonstrate workplace } \\
\text { safety behaviour. }\end{array}$ & $\begin{array}{l}\text { Demonstrates an understanding } \\
\text { of workplace health and safety } \\
\text { by their behaviour. }\end{array}$ & $\begin{array}{l}\text { Actively promotes workplace } \\
\text { health and safety behaviour in } \\
\text { others. }\end{array}$ \\
\hline
\end{tabular}


APPENDIX B: EXAMPLE OF AN INITIAL RUBRIC [11][20][13]

\begin{tabular}{|c|c|c|c|c|c|}
\hline \multirow{2}{*}{$\begin{array}{l}\text { Graduate } \\
\text { Attribute: } \\
\text { Focus Area }\end{array}$} & Level descriptor & Fails to meet expectations & Minimally meets expectations & Adequately meets expectations & Exceeds expectations \\
\hline & $\begin{array}{l}\text { Example score } \\
\text { (Course Specific) }\end{array}$ & $\begin{array}{l}F-D \\
(0-60 \%)\end{array}$ & $\begin{array}{l}C \\
(60-70 \%)\end{array}$ & $\begin{array}{l}B \\
(70-80 \%)\end{array}$ & $\begin{array}{l}A \\
(>80 \%)\end{array}$ \\
\hline & $\begin{array}{l}\text { Etiquette, Responsibility and } \\
\text { Practice: } \\
\text { Ability to exhibit professional } \\
\text { behaviour and practice, and to } \\
\text { take responsibility for own } \\
\text { actions. }\end{array}$ & $\begin{array}{l}\text { Frequently absent from class } \\
\text { and is generally not collegial to } \\
\text { fellow students, staff, and } \\
\text { faculty. Blames others for own } \\
\text { issues and problems. Student } \\
\text { has been caught cheating or } \\
\text { plagiarizing the work of others. } \\
\text { Student is unaware or ignores } \\
\text { workplace saftely principles. }\end{array}$ & $\begin{array}{l}\text { Sometimes exhibits } \\
\text { unprofessional behavior; is } \\
\text { sometimes absent from class } \\
\text { without reason. Doesn't } \\
\text { recognize the need to take } \\
\text { personal responsibility for } \\
\text { his/her actions. Does not model } \\
\text { professional behavior among } \\
\text { peers and faculty. Aware of } \\
\text { workplace safety principles, but } \\
\text { may not always practice them. }\end{array}$ & $\begin{array}{l}\text { Exhibits professional behavior; } \\
\text { is sometimes absent from class, } \\
\text { but with a reason. Recognizes } \\
\text { the need to take personal } \\
\text { responsibility for his/her } \\
\text { actions, but doesn't always do } \\
\text { so. Is somewhat professional } \\
\text { among peers and faculty. } \\
\text { Student is aware of and abides } \\
\text { by workplace safety principles. }\end{array}$ & $\begin{array}{l}\text { Punctual, professional, and } \\
\text { collegial; attends classes } \\
\text { regularly. Takes personal } \\
\text { responsibility for his/her } \\
\text { actions, and consistently } \\
\text { demonstrates professional } \\
\text { behavior among peers and } \\
\text { faculty at all times. Student } \\
\text { models exemplary workplace } \\
\text { safety behaviour. }\end{array}$ \\
\hline & $\begin{array}{l}\text { Codes: } \\
\text { Awareness of and ability to } \\
\text { apply the APEGM Code of Ethics } \\
\text { and the } U \text { of M Student Code of } \\
\text { Conduct. }\end{array}$ & $\begin{array}{l}\text { Unaware of the APEGM Code of } \\
\text { Ethics and the UofM Student } \\
\text { Code of Conduct. }\end{array}$ & $\begin{array}{l}\text { Aware of the existence of the } \\
\text { APEGM Code of Ethics and the } \\
\text { UofM Student Code of Conduct. }\end{array}$ & $\begin{array}{l}\text { Understands and abides by the } \\
\text { APEGM Code of Ethics and the } \\
\text { UofM Student Code of Conduct. }\end{array}$ & $\begin{array}{l}\text { Demonstrates exemplary } \\
\text { understanding and rigorously } \\
\text { abides by the APEGM Code of } \\
\text { Ethics and the UofM Student } \\
\text { Code of Conduct. }\end{array}$ \\
\hline & $\begin{array}{l}\text { Evaluation and Judgment: } \\
\text { Ability to evaluate and judge a } \\
\text { situation in practice or a case } \\
\text { study using facts and the } \\
\text { APEGM Code of Ethics. }\end{array}$ & $\begin{array}{l}\text { Evaluates and judges a situation } \\
\text { in practice or in a case study } \\
\text { using a biased perspective } \\
\text { without objectivity.. }\end{array}$ & $\begin{array}{l}\text { Evaluates and judges a situation } \\
\text { in practice or in a case study } \\
\text { using personal understanding of } \\
\text { the situation, possibly applying } \\
\text { a personal value system. }\end{array}$ & $\begin{array}{l}\text { Evaluates and judges a situation } \\
\text { in practice or in a case study } \\
\text { using a basic understanding of } \\
\text { the facts and the APEGM Code } \\
\text { of Ethics. }\end{array}$ & $\begin{array}{l}\text { Evaluates and judges a situation } \\
\text { in practice or in a case study } \\
\text { skillfully using facts and the } \\
\text { APEGM Code of Ethics. }\end{array}$ \\
\hline & $\begin{array}{l}\text { Professional Practice, Safety } \\
\text { and Risk Management: } \\
\text { Awareness of professional } \\
\text { practice issues such as safety } \\
\text { and risk managament and their } \\
\text { importance in the protection of } \\
\text { the public and the public } \\
\text { interest. }\end{array}$ & $\begin{array}{l}\text { Is unfamiliar with professional } \\
\text { practice issues such as safety } \\
\text { and risk managament and their } \\
\text { importance in the protection of } \\
\text { the public and the public } \\
\text { interest. }\end{array}$ & $\begin{array}{l}\text { Knows about some of the } \\
\text { professional issues that } \\
\text { influence the practice of } \\
\text { engineering, such as safety and } \\
\text { risk managament and their } \\
\text { importance to the public and } \\
\text { the public interest. }\end{array}$ & $\begin{array}{l}\text { Aware of the professional issues } \\
\text { that influence the practice of } \\
\text { engineering, such as safety and } \\
\text { risk managament and their } \\
\text { importance to the public and } \\
\text { the public interest. }\end{array}$ & $\begin{array}{l}\text { Fully aware of the professional } \\
\text { issues that influence the } \\
\text { practice of engineering, such as } \\
\text { safety and risk managament and } \\
\text { their importance to the public } \\
\text { and the public interest. }\end{array}$ \\
\hline & $\begin{array}{l}\text { Professional and Technical } \\
\text { Societies: } \\
\text { Ability to participate in } \\
\text { professional and/or technical } \\
\text { societies available to the } \\
\text { student body. }\end{array}$ & $\begin{array}{l}\text { Does not show any interest in } \\
\text { professional and/or technical } \\
\text { societies. }\end{array}$ & $\begin{array}{l}\text { Occasionally participates in the } \\
\text { activities of local professional } \\
\text { and technical societies. }\end{array}$ & $\begin{array}{l}\text { Participates in professional and } \\
\text { technical societies available to } \\
\text { the student body. }\end{array}$ & $\begin{array}{l}\text { Participates and takes a } \\
\text { leadership role in professional } \\
\text { and technical societies } \\
\text { available to the student body. }\end{array}$ \\
\hline & $\begin{array}{l}\text { Registered Professional } \\
\text { Engineer: } \\
\text { Knowledge of the need for } \\
\text { being a Registered Professional } \\
\text { Engineer }\end{array}$ & $\begin{array}{l}\text { Demonstrates no known benefit } \\
\text { for becoming a P.Eng. }\end{array}$ & $\begin{array}{l}\text { Demonstrates partial } \\
\text { understanding of the need for } \\
\text { being a P.Eng. }\end{array}$ & $\begin{array}{l}\text { Demonstrates adequate } \\
\text { understanding of the need for } \\
\text { registration and the difference } \\
\text { it makes in the target } \\
\text { engineering profession. }\end{array}$ & $\begin{array}{l}\text { Demonstrates sophisticated } \\
\text { understanding of the need for } \\
\text { Professional Registration and } \\
\text { the value it brings to an } \\
\text { engineering career. }\end{array}$ \\
\hline & $\begin{array}{l}\text { Procedure for Becoming } \\
\text { P.Eng.: } \\
\text { Awareness of methods for } \\
\text { becoming a Registered } \\
\text { Professional Engineer. }\end{array}$ & $\begin{array}{l}\text { No awareness, grasps at } \\
\text { concepts. }\end{array}$ & $\begin{array}{l}\text { Outlines a general procedure } \\
\text { but does not clearly identify } \\
\text { methods. }\end{array}$ & $\begin{array}{l}\text { Somewhat clear definition of } \\
\text { solution, procedure, and } \\
\text { methods. }\end{array}$ & $\begin{array}{l}\text { Clear definition of procedure } \\
\text { for becoming a P.E., the grades, } \\
\text { and understanding of } \\
\text { responsibility limits within each } \\
\text { grade. }\end{array}$ \\
\hline & $\begin{array}{l}\text { Staying Current: } \\
\text { Awareness of the different } \\
\text { methods for staying current } \\
\text { within the engineering } \\
\text { profession. }\end{array}$ & $\begin{array}{l}\text { No awareness or appreciation } \\
\text { for the value of staying current. }\end{array}$ & $\begin{array}{l}\text { Some awareness of the need for } \\
\text { keeping current. }\end{array}$ & $\begin{array}{l}\text { Somewhat clear about the } \\
\text { methods for staying current. } \\
\text { Aware of the role that } \\
\text { professional organizations play } \\
\text { in lifelong learning. }\end{array}$ & $\begin{array}{l}\text { Clear awareness of the methods } \\
\text { for staying current and acutely } \\
\text { aware of the role that } \\
\text { professional organizations play } \\
\text { in lifelong learning. }\end{array}$ \\
\hline
\end{tabular}

The rubrics have evolved from the following sources: Rubrics [Adapted] Reprinted [or Excerpted] with permission from Assessing Outcomes and Improving Achievement: Tips and tools for Using Rubrics, edited by Terrel L. Rhodes. Copyright 2010 by the Association of American Colleges and Universities. Informed by University of Delaware College of Engineering Civil \& Environmental Engineering ABET Scoring Rubrics for Program Outcomes: Outcome 8: An understanding of Professional and ethical responsibility. Retrieved on October 9, 2013 from:

http://www.ce.udel.edu/ABET/Current\%20Documentation/Outcome 8.html. Informed by Rubrics for Outcome Assessment. Retrieved on October 9, 2013 from:

http://webcache.googleusercontent.com/search?q=cache:4Gwd7haic2wJ:www.bae.uky.edu/academics/abet/Rubrics\%2520Draft\%2520July\%25202012.d $\underline{\mathrm{ocx}}+\& \mathrm{~cd}=1 \& \mathrm{hl}=\mathrm{en} \& \mathrm{ct}=\mathrm{clnk} \& \mathrm{gl}=\mathrm{ca} \& \mathrm{client}=\mathrm{safari}$ 